\title{
An optimal put option contract for a reverse supply chain: case of remanufacturing capacity uncertainty
}

\author{
Alireza Bakhshi ${ }^{1} \cdot$ Jafar Heydari $^{1}$
}

Accepted: 20 March 2021

(C) The Author(s), under exclusive licence to Springer Science+Business Media, LLC, part of Springer Nature 2021

\begin{abstract}
Reverse supply chain (RSC) management can be implemented to ameliorate environmental and economic goals simultaneously. In 2020, the devastating influences generated by the COVID-19 global pandemic had established high uncertainty in the manufacturers' capacity, which can hinder the fulfillment of such goals. To address such a problem, in this research, we analyze a two-echelon RSC, including a re-manufacturer who, despite facing the remanufacturing capacity uncertainty, remanufactures eligible obsolete products, then re-enters the marketplace, and a collector who accumulates eligible obsolete products from consumers. We survey centralized and decentralized decisions, and also a condition where the collector, as a Stackelberg game leader, offers a put option contract as a risk-sharing approach and decides on both option and exercise prices; in return, the re-manufacturer determines the order quantity. Contrary to previous studies in which the value of option contracts has been analyzed under demand disruptions, this paper aims to address the performance of a put option contract to mitigate the remanufacturing capacity uncertainty in an RSC. Our results demonstrate that by offering the put option contract and determining the option price as nearly low as the marginal refund cost, not only can the collector motivate the re-manufacturer to augment its order quantity but both parties also attain a win-win profit-sharing outcome. Besides, the customized put option contract can achieve Pareto-improving channel coordination in the condition of remanufacturing capacity uncertainty.
\end{abstract}

Keywords Channel coordination · Remanufacturing capacity uncertainty $\cdot$ Reverse supply chain · Put option contract

Jafar Heydari

J.Heydari@ut.ac.ir

Alireza Bakhshi

alirezabakhshi@ut.ac.ir

1 School of Industrial Engineering, College of Engineering, University of Tehran, Tehran, Iran 


\section{Introduction}

The ever-increasing changes and developments in the business world and the new requirements of production, as well as the importance of environmental issues in the present age, have developed new attitudes around the subject of logistics called RSC (Weraikat et al., 2016). RSCs deal with a set of activities that get end-of-life products from consumers and then bring them back to re-manufacturers in order to refurbish (Li et al., 2019; Soleimani et al., 2016). Since the implementation of activities related to RSCs accompanies abundant advantages, e.g., economic, social, and environmental (Feitó-Cespón et al., 2017; Golinska-Dawson \& Pawlewski, 2018; Govindan et al., 2014, 2019; Mishra \& Singh, 2020; Paksoy et al., 2010; Zarbakhshnia et al., 2020); remanufacturing and recycling obsolete products doubles the importance of paying attention to RSCs (Heydari et al., 2018; Hua et al., 2019a). For example, Apple is one of the extraordinary instances of professional management in RSCs (Jena et al., 2019; Liu et al., 2018; Wang et al., 2019c). Apple will propose discounts on its novel product if consumers bring back old products (Govindan \& Popiuc, 2014; Shu et al., 2018). Similarly, by considering various bonuses for consumers, other companies (e.g., Dell, HP, Nokia, IBM, and the like) gather obsolete products to be able to use various pieces after retrieving their value (Feng et al., 2017; Heydari \& Ghasemi, 2018; Hosseini-Motlagh et al., 2019; Xie et al., 2017). RSC management is widespread not only in electronic industries but also in other industries such as clothing. As a real case, H\&M accumulates and uses old clothes in order to make a recycled clothing line. Furthermore, the COVID-19 pandemic has resulted in an imbalance between supply/demand-sides so that manufacturers and retailers faced hurdles in realizing an explicit amount of production capacity and market demand, respectively (Tirkolaee et al., 2021). Such examples indicate that notwithstanding the presence of possible existing uncertainties in RSCs (e.g., the risk of remanufacturing capacity or product quality), RSC management can undoubtedly result in improving environmental and economic goals (Dev et al., 2020; Goli et al., 2020; Kushwaha et al., 2020; Özçelik et al., 2020; Özceylan \& Paksoy, 2014; Uğurlu, 2018, 2020).

RSCs can be managed through a variety of mechanisms. For instance, in order to manage RSCs that deal with demand volatility, Mafakheri and Nasiri (2013) and Sun et al. (2019) used revenue-sharing contracts, and Heydari et al. (2017) applied a discount contract. However, most studies have often used revenue-sharing and discount to manage RSCs, in this research, we analyze the value of option contract, where a collector proposes a put option contract to a re-manufacturer who deals with remanufacturing capacity uncertainty. Put option contracts, as one type of option contracts, can be used between upstream and downstream. According to this contract, the downstream gets the right (not obligation) to sell certain products with an exercise price as a refund cost (Wang et al. 2019b). Note that option contracts have been frequently used to hedge against demand uncertainty (e.g., Arani et al., 2016; Hu et al., 2018; Wang \& Chen, 2017), while their value has not yet been investigated to tackle the remanufacturing capacity uncertainty. Therefore, we develop a customized put option contract and examine its performance notably in mitigating the remanufacturing capacity disruptions. Thus, this research addresses the following questions:

- Is a put option contract capable of coordinating an RSC with remanufacturing capacity uncertainty? What are the specifications of optimal contract terms?

- Can both parties make an extra profit under the put option contract? 
Motivated by answering such questions, we analyze a two-echelon RSC, including a remanufacturer who, despite facing the remanufacturing capacity uncertainty, can remanufacture eligible obsolete products, and a collector who gathers such items from consumers. We survey the influence of a put option contract, where the collector is a Stackelberg game leader. Under the put option contract, the re-manufacturer is able to reserve products with an option price in advance, then it can exercise them with an exercise price based on its need.

We demonstrate that under either high or low remanufacturing capacity volatility, not only can the put option contract coordinate the RSC, but both parties also achieve a win-win profit-sharing situation. This conclusion is entirely new when uncertainty in RSCs is concerned with the remanufacturing capacity. To clarify this, by distinguishing between the centralized system and the decentralized system, we display the system's detriment. In the decentralized system, the re-manufacturer's order quantity from the collector is lower than the centralized system. Afterward, the value of put option contract, which works as a risk-sharing module thanks to the adjustment of contract terms, i.e., option and exercise prices, is characterized. Our results indicate that by offering the put option contract and determining the option price as nearly low as the marginal refund cost, the collector can motivate the re-manufacturer to augment its order quantity, i.e., close to the centralized system.

The rest of the paper is organized as follows. We review previous studies in Sect. 2. In Sect. 3, we express the modeling approach and assumptions. Mathematical models concerned with centralized and decentralized decisions are proposed in Sect. 4. Mathematical models and optimal decisions of each party are presented under the put option contract in Sect. 5. In Sect. 6, we address numerical examples, sensitivity analyses, and managerial implications. Finally, we address conclusions in Sect. 7.

\section{Literature review}

This study is associated with two considerable subjects: the first one concentrates on RSC management, and the second one addresses the application of option contracts. Concerning such topics, we review previous studies and relate them to our study.

\subsection{RSC management}

Some papers addressed review of issues associated with RSCs as well as presenting classifications and strategies to deal with potential problems (De Giovanni, 2014; Govindan \& Soleimani, 2017; Govindan et al., 2013; Guo et al., 2017; Mardani et al., 2020; Sasikumar \& Kannan, 2009; Van Engeland et al., 2020). Revenue-sharing contracts are one of the applicable contracts used in RSCs management. Heydari and Ghasemi (2018) and Heydari et al. (2018) surveyed a revenue-sharing contract in the RSC involved in uncertain remanufacturing capacity. By and large, many previous studies have investigated a revenue-sharing contract in RSCs (Feng et al., 2017; Govindan \& Popiuc, 2014; Mafakheri \& Nasiri, 2013; Sun et al., 2019; Weraikat et al., 2016). Recently, Wu et al. (2020) examined a dual-channel RSC, including online and offline recycling channels, and made a revenue-sharing contract with a third-party recycler. There is a body of papers, using other contracts instead of revenue-sharing contracts. Hu et al. (2016) compared several contracts (i.e., wholesale price, subsidy, cost-pooling, indemnity, and two-stage price contracts) in an RSC. Heydari et al. (2017) proposed a discount contract in order to manage an RSC, while the effect 
of potential government roles (e.g., subsidy and tax) has been explored as well. In other similar papers, the effect of government subsidy on pricing policies has been surveyed in supply chains (Hong et al., 2016; Li et al., 2020b; Shu et al., 2018; Wang et al., 2019d). Hosseini-Motlagh et al. (2019) addressed the combined two-part-tariff contract in a dualchannel RSC under demand uncertainty along with considering environmental, economic, and social factors. Our study develops a put option contract as a new contract in the presence of remanufacturing capacity disruption in an RSC.

Some studies considered cooperative viewpoints by analyzing game models in RSCs (Chen et al., 2019; Hua et al., 2019a; Li et al., 2017a). Recently, Li et al. (2019) surveyed three models in an RSC based on offline, online, and mixed channels so that optimal recycling prices and quantities have been determined given uncertain demand. Similarly, the current research uses a game-theoretic methodology.

\subsection{Option contracts}

In this section, we examine previous studies concerned with the application of option contracts in the context of supply chain management. This predominantly incorporates using option contracts to address inventory management (Biswas \& Avittathur, 2019; Eriksson, 2019; John et al., 2020; Liang et al., 2012; Ritchken \& Tapiero, 1986) and tackling disruptions in either demand (Anderson et al., 2017; Chen et al., 2014, 2017; Erkoc \& Wu, 2005; Fu et al., 2017; Hua et al., 2019b; Nosoohi \& Nookabadi, 2016; Wang \& Chen, 2017; Wang \& Tsao, 2006; Zhao et al., 2013) or production yield rate (Li et al., 2017b; Luo \& Chen, 2017; Xu, 2010). Recently, Hu et al. (2019) examined a put option contract and a buyback contract in a relief supply chain. In another paper, by applying an option contract, Hu et al. (2018) developed a model where demand is contingent on the retail price. In another similar research in which demand is formed based on price, Wang and Chen (2018) considered a newsvendor problem along with a put option contract. To deal with uncertain demand and price, Li (2020a) examined quantity flexibility and option contracts in mitigating such disruptions. Arani et al. (2016) investigated a combination of the option and revenue-sharing contracts as a hybrid contract in a dyadic supply chain under random demand and product price. Based on the level of information relevant to potential uncertainties, Köle and Bakal (2017) and Zhao et al. (2018) surveyed option contracts in a two-echelon supply chain to evaluate outcomes under various access levels of information. In some studies, the customer returns policy combined with option contracts have been simultaneously considered. Wang et al. (2017) and Wang et al. (2019a) analyzed the influence of customer returns and option contracts on ordering/pricing policy in a supply chain with stochastic demand. Similarly, Wang et al. (2019b) addressed a game-theoretic model associated with a put option contract under demand uncertainty and customer returns. Note that previous papers have addressed member's decisions in forward supply chains with demand uncertainty, while the current study concentrates on remanufacturing capacity uncertainty and surveys each party's optimal decisions in an RSC.

\subsection{Research gap}

Table 1 demonstrates the differences and similarities of previous studies with the current research. As can be seen in Table 1, previous studies have mainly examined the value of option contracts in forward supply chains under stochastic demand; in return, this study 


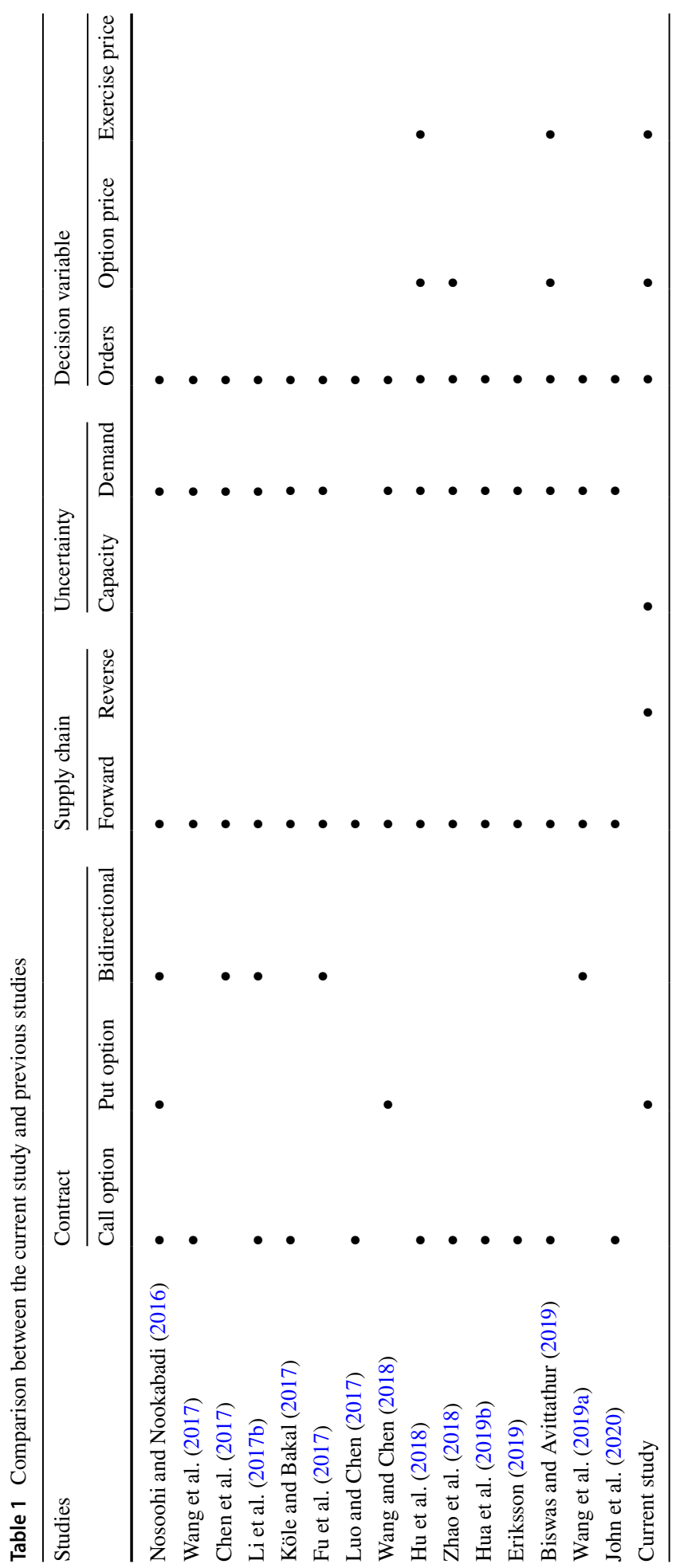


addresses the influence of such a contract (i.e., put option contract) on an RSC facing remanufacturing capacity uncertainty. In other words, contrary to prior papers, uncertainty has shifted from demand-side to supply-side. Furthermore, from the proposed contract perspective, we can confirm that previous studies mainly have assumed fixed and pre-agreed option contract terms, and negotiation between parties to find optimal contract terms (i.e., option and exercise prices) has less been investigated, even in forward logistics. Only a few studies have addressed optimal option contract terms merely in the condition of random demand (e.g., Biswas \& Avittathur, 2019; Hu et al., 2018; Zhao et al., 2018). Different from previous literature, this study focuses on addressing optimal ordering policies along with optimal option contract terms dealing with remanufacturing capacity uncertainty in an RSC.

\section{Problem description}

In this research, we consider a two-echelon RSC, including a re-manufacturer (indicated by $M$ ) who can remanufacture obsolete products that are eligible to get into the remanufacturing process and re-enter the marketplace, and a collector (indicated by $C$ ) who gathers obsolete products from consumers, albeit those which can be entered into the remanufacturing process (i.e., after examination of returned products). Let $p$ indicate the price of a remanufactured product; revenue for the re-manufacturer per remanufactured item sold in the marketplace. Note that the re-manufacturer buys obsolete products at $C_{r} /$ unit, then remanufactures at $C_{r e}$ /unit. We assume that the remanufacturing capacity in such a system, prone to disruption, namely, the re-manufacturer might be unable to remanufacture all returned eligible obsolete products. Besides, the collector pays a cost to consumers in bringing back end-of-life products; let us denote $C_{a}$ /unit as a refund cost. The notations listed in mathematical models are as follows:

\begin{tabular}{|c|c|}
\hline Notation & Description \\
\hline$c$ & $\begin{array}{l}\text { A non-negative continuous random variable, which expresses the remanu- } \\
\text { facturing capacity with probability density function } f(x) \text { and cumulative } \\
\text { distribution function } F(x)\end{array}$ \\
\hline$C_{r}$ & Recycling cost which is paid to the collector to get eligible obsolete products \\
\hline$C_{e}$ & Examination cost per unit by the collector \\
\hline$a$ & Acceptance rate of returning products by the collector \\
\hline$C_{h}$ & Holding cost per unit stored by the collector \\
\hline$C_{r e}$ & Remanufacturing cost per unit \\
\hline$C_{i}$ & Preparation cost per unit for remanufacturing by the re-manufacturer \\
\hline$C_{t}$ & Transportation cost per unit delivered to the re-manufacturer \\
\hline$C_{a}$ & Refund cost paid to consumers due to bringing back obsolete products \\
\hline$p$ & Price of remanufactured product per unit in order to re-enter the market \\
\hline$v$ & Salvage value per unit \\
\hline \multicolumn{2}{|c|}{ Decision variables } \\
\hline$Q_{d}$ & Order quantity under the decentralized model \\
\hline$Q_{c}$ & Order quantity under the centralized model \\
\hline$Q_{p}$ & Option amount in the put option contract \\
\hline$o$ & Option price \\
\hline$e$ & Exercise price \\
\hline
\end{tabular}


Note that Subscripts ' $d$ ', ' $c$ ', and ' $p$ ' in decision variables denote the decentralized, centralized, and put option contract, respectively. Consider a model without put option contract, the re-manufacturer has to place a definite purchase from the collector, namely, the re-manufacturer decides on order quantity from the collector (i.e., $Q_{d}$ ), but the collector might not provide the entire orders due to being non-eligible returned products (i.e., $a \neq 1$ ). Therefore, all amounts which are eligible (i.e., $Q_{d} a$ ), are merely delivered to the re-manufacturer. Indeed, it is most likely that what the re-manufacturer has ordered will be received in smaller quantities. At the same time, for the sake of remanufacturing capacity uncertainty, after realizing the remanufacturing capacity, the re-manufacturer might encounter either over-stocking or under-stocking. If the number of eligible obsolete products is more, only products as much as the remanufacturing capacity will be remanufactured; whereby, additional products have to be sold at a negligible price. Hence, the re-manufacturer should trade-off the contingency of over-stocking in addition to the risk of under-stocking. However, as the re-manufacturer will not incur any penalty when faces under-stocking, it usually tends to order a low amount to lessen the risk of over-stocking. Such inefficiency can be moderated if the collector considers an incentive mechanism. Figure 1 illustrates the flow of materials in the investigated RSC.

Now consider a condition where the collector offers a put option contract with option price o/unit and exercise price e/unit in place of a regular definite purchase in order to encourage the re-manufacturer to order more. In this way, the re-manufacturer is able to reserve eligible option amounts (i.e., $Q_{p} a$ ). Accordingly, whenever the remanufacturing capacity is specified, the option amount can be exercised with exercise price $e /$ unit in case of under-stocking; whereby, the re-manufacturer can avoid facing over-stocking as well. Note that the option price will not be refunded to the re-manufacturer if reserved options are not exercised. In the model with put option contract, the collector acts as a leader of the Stackelberg game who decides on contract terms (i.e., $o$ and $e$ ), and given specified terms, the re-manufacturer, as a follower, determines option amount. To eschew trivial cases, we assume $p>e+o>C_{a}$.

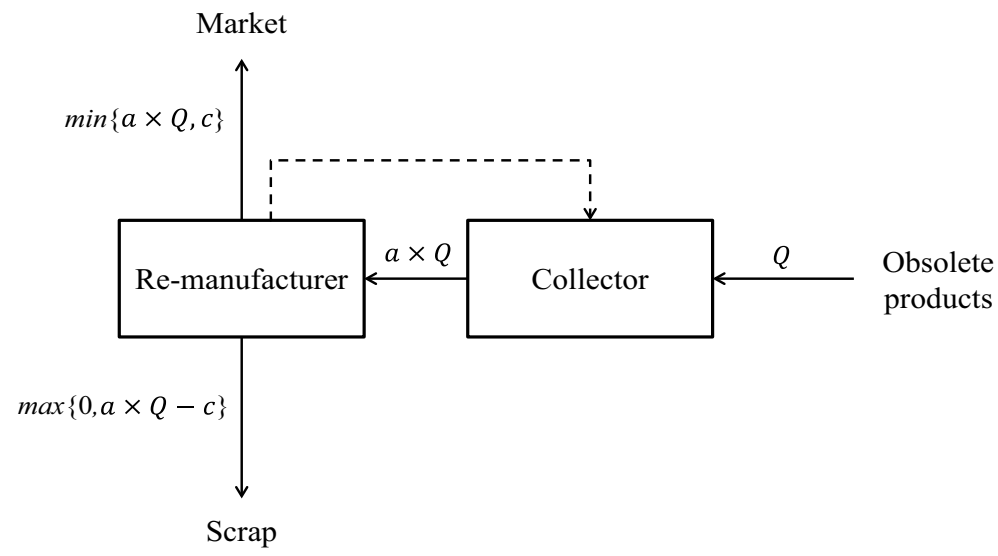

Fig. 1 Material flow in the investigated RSC 


\section{Mathematical models without put option contract}

In this section, to comprehend the advantage of put option contract, we first survey models under two conditions when RSC parties do not adopt any contract. The first case is a centralized scenario in which the order quantity merely maximizes the whole system's profit, and the second case is a decentralized scenario in which the re-manufacturer specifies the order quantity to maximize its own profit. Note that although the conceptual framework of this research is in line with previous studies on RSC management (e.g., Govindan \& Popiuc, 2014; Heydari \& Ghasemi, 2018; Heydari et al., 2018), the models presented in the decentralized and centralized scenarios are original. The aforementioned studies analyzed decisions concerned with RSC management about how to devote rewards to consumers for the sake of bringing back obsolete products, while the present research examines such an issue from the perspective of ordering policy.

\subsection{Centralized decision-making}

In centralized decision-making, all decisions are aligned with the interests of the integrated system so that the RSC's profit is maximized. In other words, all parties work together to maximize the whole system profit. However, the cooperation of parties as an integrated system seems to be completely insubstantial and optimistic, it just evokes the maximum conceivable system's profit. Afterward, we use its results in the course of examining the fruitfulness of put option contracts in the decentralized channel. According to the remanufacturing capacity realization $c$, the system's profit under centralized decision can be formulated as:

$$
\Pi_{S C}\left(Q_{c}\right)= \begin{cases}\left(p-C_{r e}\right) c-C_{i} Q_{c} a+v\left(Q_{c} a-c\right)-Q_{c} a\left(C_{a}+\frac{C_{e}}{a}+C_{t}+C_{h}\right) & Q_{c} a>c \\ p Q_{c} a-C_{r e} Q_{c} a-C_{i} Q_{c} a-Q_{c} a\left(C_{a}+\frac{C_{e}}{a}+C_{t}+C_{h}\right) & Q_{c} a \leq c\end{cases}
$$

In Eq. (1), the collector examines all returned obsolete products and accepts amounts that can be used in the remanufacturing process; after storage, eligible obsolete products will be sent to the re-manufacturer. Finally, the re-manufacturer prepares the products to initiate the remanufacturing process. Hence, when there is no adequate remanufacturing capacity, i.e., $Q_{c} a>c$, only $c$ items can be entered into the remanufacturing process. Thus, the system is keen on the marginal profit $p-C_{r e}$, and $Q_{c} a-c$ items have to be sold as scrap at a trivial price. On the other hand, term $Q_{c} a \leq c$ demonstrates that the whole obsolete items gathered by the collector will get into the remanufacturing process due to sufficient remanufacturing capacity, and no items need to be sold as scrap. By and large, the integrated system specifies $Q_{c}$ to maximize its expected profit; $\max _{Q_{c}} E\left[\Pi_{S C}\left(Q_{c}\right)\right]$, where

$$
\begin{aligned}
E\left(\Pi_{S C}\left(Q_{c}\right)\right)= & \left(p-C_{r e}\right)\left(\int_{0}^{Q_{c} a} c f(c) d c+\int_{Q_{c} a}^{\infty} Q_{c} a f(c) d c\right)+v\left(\int_{0}^{Q_{c} a}\left(Q_{c} a-c\right) f(c) d c\right) \\
& -C_{i} Q_{c} a-Q_{c} a\left(C_{a}+\frac{C_{e}}{a}+C_{t}+C_{h}\right)
\end{aligned}
$$


Theorem 1 The integrated system's expected profit is a concave function in $Q_{c}$ and the optimal $Q_{c}$ is determined as:

$$
Q_{c}^{*}=\frac{F^{-1}\left(\frac{p-C_{r e}-C_{i}-C_{a}-\frac{C_{e}}{a}-C_{t}-C_{h}}{p-C_{r e}-v}\right)}{a}
$$

Proof To show concavity, from Eq. (2), we calculate $\frac{\partial^{2} E\left[\Pi_{S C}\left(Q_{c}\right)\right]}{\partial Q_{c}{ }^{2}}$. Since $\frac{\partial^{2} E\left[\Pi_{S C}\left(Q_{c}\right)\right]}{\partial Q_{c}{ }^{2}}=-a^{2}\left(p-C_{r e}-v\right) f\left(Q_{c} a\right)<0$; therefore, the RSC's profit function is strictly concave in $Q_{c}$. Besides, $Q_{c}{ }^{*}$ is to be calculated through the first-order optimality state, i.e., $\frac{\partial E\left[\Pi_{S C}\left(Q_{c}\right)\right]}{\partial Q_{c}}=\left(p-C_{r e}\right)\left(\int_{Q_{c} a}^{\infty} f(c) d(c)\right)+v\left(\int_{0}^{Q_{c} a} f(c) d(c)\right)-\left(C_{a}+\frac{C_{e}}{a}+C_{t}+C_{h}+C_{i}\right)=0$.

Proof is complete.

Note that the principal takeaway acquired in Theorem 1 is that $F\left(Q_{c}\right)$ corresponds to a newsvendor problem, namely, in case of remanufacturing capacity volatility, the trade-off between the overage and underage costs is performed based on $\left(C_{a}+\frac{C_{e}}{a}+C_{t}+C_{h}\right)$. The underage cost is $p-\left(C_{r e}+C_{i}+C_{a}+\frac{C_{e}}{a}+C_{t}+C_{h}\right)$ per unit and the overage cost is $\left(C_{i}+C_{a}+\frac{C_{e}}{a}+C_{t}+C_{h}\right)-v$ per unit. Hence, $Q_{c}{ }^{*}$ solves $\frac{F^{-1}\left(\frac{p-C_{r e}-C_{i}-C_{a}-\frac{C_{e}}{a}-C_{t}-C_{h}}{p-C_{r e}-v}\right)}{a}$. The following corollary demonstrates why the integrated system may not bring about a win-win situation for RSC's parties.

Corollary 1 Under the centralized decision-making, the re-manufacturer's order is not dependent on $C_{r}$.

Proof By using Eq. (3), since $\frac{\partial Q_{c}{ }^{*}}{\partial C_{r}}=0$; therefore, $Q_{c}{ }^{*}$ is non-sensitive to $C_{r}$. Proof is complete.

Corollary 1 expresses that since calculating $Q_{c}{ }^{*}$ results in maximizing the whole system's profit, such choice is somehow up to the re-manufacturer decision. Hence, if the remanufacturer is unable to maximize its own profit through $Q_{c}{ }^{*}$, not only will it not make such a decision but it also places order quantity in a way to maximize its profit.

Corollary 2 If operational costs such as $C_{r e}, C_{e}, C_{a}$, and $C_{i}$ increases, $Q_{c}^{*}$ will be diminished.

Proof Since $\frac{\partial Q_{c}^{*}}{\partial C_{i}}=\frac{\partial Q_{c}^{*}}{\partial C_{a}}=\left[\frac{-1}{f\left(Q_{d} a\right)\left(p-C_{r e}-v\right) a}\right]<0, \quad \frac{\partial Q_{c}^{*}}{\partial C_{e}}=\left[\frac{-1}{f\left(Q_{d} a\right)\left(p-C_{r e}-v\right) a^{2}}\right]<0, \quad$ and $\frac{\partial Q_{c}^{*}}{\partial C_{r e}}=-\left[\frac{C_{i}+C_{a}+\frac{C_{e}}{a}+C_{t}+C_{h}-v}{f\left(Q_{c} a\right)\left(p-C_{r e}-v\right)^{2} a}\right]<0, Q_{c}^{*}$ is a decreasing function in operational costs. Proof is complete. 


\subsection{Decentralized decision-making}

According to decentralized decision-making, contrary to decisions based on the interests of whole system, the re-manufacturer independently determines $Q_{d}$. Given the order quantity $Q_{d}$ and the realization of remanufacturing capacity $c$, the re-manufacturer's profit can be formulated as follow:

$$
\Pi_{M}\left(Q_{d}\right)= \begin{cases}\left(p-C_{r e}\right) c-\left(C_{r}+C_{i}\right) Q_{d} a+v\left(Q_{d} a-c\right) & Q_{d} a>c \\ \left(p-C_{r e}\right) Q_{d} a-\left(C_{r}+C_{i}\right) Q_{d} a & Q_{d} a \leq c\end{cases}
$$

Note that Eq. (4) is analogous to Eq. (1) except that the recycling cost $C_{r}$ is used instead of a set of costs incurred by the collector, i.e., holding, transportation, examination, and refund costs. Therefore, the re-manufacturer decides on $Q_{d}$ to maximize its expected profit function; $\max _{Q_{d}} E\left[\Pi_{M}\left(Q_{d}\right)\right]$, where

$$
E\left(\Pi_{M}\left(Q_{d}\right)\right)=\left(p-C_{r e}\right)\left(\int_{0}^{Q_{d} a} c f(c) d c+\int_{Q_{d} a}^{\infty} Q_{d} a f(c) d c\right)-Q_{d} a\left(C_{r}+C_{i}\right)+v\left(\int_{0}^{Q_{d} a}\left(Q_{d} a-c\right) f(c) d c\right)
$$

Theorem 2 The re-manufacturer expected profit function is concave in $Q_{d}$ and $Q_{d}{ }^{*}$ is specified by:

$$
Q_{d}^{*}=\frac{F^{-1}\left(\frac{p-C_{r e}-C_{r}-C_{i}}{p-C_{r e}-v}\right)}{a}
$$

Proof Since the second-order derivative of Eq. (5) in $Q_{d}$ is negative (i.e., $\left.\frac{\partial^{2} E\left[\Pi_{M}\left(Q_{d}\right)\right]}{\partial Q_{d}{ }^{2}}=-a^{2}\left(p-C_{r e}-v\right) f\left(Q_{d} a\right)<0\right), E\left[\Pi_{M}\left(Q_{d}\right)\right]$ is concave in $Q_{d}$. Furthermore, the proof of Eq. (6) is identical to Theorem 1 $\left(\right.$ i.e., $\left.\frac{\partial E\left[\Pi_{M}\left(Q_{d}\right)\right]}{\partial Q_{d}}=\left(p-C_{r e}\right)\left(\int_{Q_{d} a}^{\infty} f(c) d(c)\right)+v\left(\int_{0}^{Q_{d} a} f(c) d(c)\right)-\left(C_{r}+C_{i}\right)=0\right)$. Proof is complete.

Note that the principal takeaway from Theorem 2 is similar to Theorem 1 so that in case of remanufacturing capacity failure, the trade-off between the overage and underage costs is carried out based on $C_{r}$. The underage cost is $p-\left(C_{r e}+C_{i}+C_{r}\right)$ per unit and the overage cost is $\left(C_{i}+C_{r}\right)-v$ per unit. Hence, $Q_{d}{ }^{*}$ solves $\frac{F^{-1}\left(\frac{p-C_{r e}-C_{r}-C_{i}}{p-C_{r e}-v}\right)}{a}$.

Now let us characterize the collector's profit function in the decentralized model. In respect of the order quantity $Q_{d}$, due to delivering all eligible returned products, the collector's profit is not dependent on the realization of remanufacturing capacity $c$ and is determined through Eq. (7), where $Q_{d}$ is the re-manufacturer's optimal order quantity in Eq. (6).

$$
\Pi_{C}=Q_{d} a\left(C_{r}-C_{a}-\frac{C_{e}}{a}-C_{h}-C_{t}\right)
$$


The collector's profit function is indicative of the income of selling obsolete products to the re-manufacturer as well as incurred costs like the cost of returned products, examination, storage, and transportation, respectively.

Corollary 3 Once $C_{r e}$ or $C_{r}$ increases, the order quantity will be reduced.

Proof Since $\frac{\partial Q_{d}{ }^{*}}{\partial C_{r}}=\left[\frac{-1}{f\left(Q_{d} a\right)\left(p-C_{r e}-v\right) a}\right]<0$ and $\frac{\partial Q_{d}{ }^{*}}{\partial C_{r e}}=-\left[\frac{C_{r}+C_{i}-v}{f\left(Q_{d} a\right)\left(p-C_{r e}-v\right)^{2} a}\right]<0$; therefore, $Q_{d}{ }^{*}$ is a decreasing function in $C_{r e}$ and $C_{r}$. Proof is complete.

Corollary 3 states that if the cost of either remanufacturing products or returned products increases, the re-manufacturer, due to not incurring more operational costs, will place fewer orders to the collector.

Corollary 4 The order quantity in the centralized decision is higher vis-a-vis decentralized decision-making.

Proof Since $C_{r}-C_{a}-\frac{C_{e}}{a}-C_{t}-C_{h}>0$ (i.e., the lack of collector detriment); hence, $F^{-1}\left(\frac{p-C_{r e}-C_{i}-C_{a}-\frac{C_{e}}{a}-C_{t}-C_{h}^{a}}{p-C_{r e}-v}\right)>F^{-1}\left(\frac{p-C_{r e}-C_{r}-C_{i}}{p-C_{r e}-v}\right)$, and we can conclude that $Q_{c}{ }^{*}>Q_{d}{ }^{*}$. Proof is complete.

The main consequence of Corollary 4 is that the decentralized decision eventuates under-stocking, which is representative of the double marginalization problem. In the decentralized model, each party has the power of its own market yet at different vertical levels so that each exerts its own markup in the prices. In the next section, we survey the effectiveness of the put option contract in ameliorating the double marginalization problem.

\section{Models with put option contract}

The decentralized model problem is that the risk of remanufacturing capacity uncertainty does not divaricate between both parties and only the re-manufacturer deals with it. Such a result brings about a lower order quantity compared to the centralized model. Therefore, the collector, as the leader of RSC, can propose a put option contract to incentivize the remanufacturer to order more as well as reinforcing the RSC surplus. In this case, the collector is able to decide on the contract terms, i.e., option and exercise prices, and in return, the re-manufacturer determines how much option to reserve. Based on backward induction, we first analyze the re-manufacturer's decision.

\subsection{Re-manufacturer's decision}

In the put option contract, first, the re-manufacturer reserves option amount $Q_{p}$ with option price $o$ /unit from the collector, and then once remanufacturing capacity is ascertained, specifies how much should be exercised with exercise price e/unit. Given the put option 
contract terms and remanufacturing capacity $c$, the re-manufacturer's profit function can be written as:

$$
\Pi_{M}\left(Q_{p}\right)= \begin{cases}p c-o Q_{p} a-e c-C_{r e} c-C_{i} c & Q_{p} a>c \\ p Q_{p} a-o Q_{p} a-e Q_{p} a-C_{r e} Q_{p} a-C_{i} Q_{p} a & Q_{p} a \leq c\end{cases}
$$

Regarding the first term in Eq. (8), i.e., $Q_{p} a>c$, the re-manufacturer merely exercises a part of options as much as the remanufacturing capacity $c$ in order not to face over-stocking. Conversely, when remanufacturing capacity is sufficient (i.e., $Q_{p} a \leq c$ ), all options, i.e., $Q_{p} a$ are exercised by the re-manufacturer to enter the remanufacturing process. To sum up, given the put option contract offered by the collector, the re-manufacturer decides on $Q_{p}$ to maximize its expected profit; $\max _{Q_{p}} E\left[\Pi_{M}\left(Q_{p}\right)\right]$, where

$$
E\left(\Pi_{M}\left(Q_{p}\right)\right)=\left(p-C_{r e}-e-C_{i}\right)\left(\int_{0}^{Q_{p} a} c f(c) d c+\int_{Q_{p} a}^{\infty} Q_{p} a f(c) d c\right)-o Q_{p} a
$$

Theorem 3 Given the put option contract, the re-manufacturer's profit function is concave in $Q_{p}$ and $Q_{p}{ }^{*}$ is as follows:

$$
Q_{p}^{*}=\frac{F^{-1}\left(\frac{p-C_{r e}-e-o-C_{i}}{p-C_{r e}-e-C_{i}}\right)}{a}
$$

Proof By calculating $\frac{\partial^{2} E\left[\Pi_{M}\left(Q_{p}\right)\right]}{\partial Q_{p}{ }^{2}}$ from Eq. (9), $\frac{\partial^{2} E\left[\Pi_{M}\left(Q_{p}\right)\right]}{\partial q_{o}{ }^{2}}=-a^{2}\left(p-C_{r e}-e-C_{i}\right) f\left(Q_{p} a\right)<0$ is obtained. Thus, the re-manufacturer's expected profit is strictly concave in $Q_{p}$. Besides, $Q_{p}{ }^{*}$ is acquired in the same way as proving the previous theorems (i.e., $\left.\frac{\partial E\left[\Pi_{M}\left(Q_{p}\right)\right]}{\partial Q_{p}}=\left(p-C_{r e}-e-C_{i}\right)\left(\int_{Q_{p} a}^{\infty} f(c) d(c)\right)-o=0\right)$. Proof is complete.

In the following, we converse about the principal takeaways obtained in Theorem 3 . Note that in the put option contract, the trade-off between the overage and underage costs is contingent on the put option contract terms (i.e., option and exercise prices), namely, in case of remanufacturing capacity uncertainty, the re-manufacturer equilibrates between over/under-reserving. The underage cost is $p-\left(o+e+C_{r e}+C_{i}\right)$ per unit, while the re-manufacturer merely incurs option price $o /$ unit in case of overage. Hence, $Q_{p}{ }^{*}$ solves $\frac{F^{-1}\left(\frac{p-C_{r e}-e-o-C_{i}}{p-C_{r e}-e-C_{i}}\right)}{a}$.

Meanwhile, under the put option contract, the option amount $Q_{p}{ }^{*}$ is declining in both $o$ (given $e$ ), and $e$ (given $o$ ), but is increasing in $p$. This signifies that the collector is able to augment the re-manufacturer's option amount through decreasing contract terms. Finally, when the collector further incentivizes the re-manufacturer to reserve options by not paying any reservation fee, the re-manufacturer's option amount takes an unrealistic shape.

Corollary 5 Under the put option contract, $Q_{p}{ }^{*}$ is decreasing either by increasing ofor a given e or increasing e for a given o, but is increasing by increasing $p$. 
Proof Since $\frac{\partial Q_{p}{ }^{*}}{\partial o}=\left[\frac{-1}{f\left(Q_{p} a\right)\left(p-C_{r e}-e-C_{i}\right) a}\right]<0, \quad \frac{\partial Q_{p}{ }^{*}}{\partial e}=\left[\frac{-o}{f\left(Q_{p} a\right)\left(p-C_{r e}-e-C_{i}\right)^{2} a}\right]<0, \quad$ and $\frac{\partial Q_{p}{ }^{*}}{\partial p}=\left[\frac{o}{f\left(Q_{p} a\right)\left(p-C_{r e}-e-C_{i}\right)^{2} a}\right]>0, Q_{p}$ is a function with a decreasing slope in both $o$ and $e$, while is a function with an increasing slope in $p$. Proof is complete.

Corollary 6 If the re-manufacturer pays no option price, its option amount will tend to be a lot.

Proof With respect to Eq. (10), we have $\lim _{o \rightarrow 0} Q_{p}{ }^{*}=\frac{F^{-1}(1)}{a}$. Since $F^{-1}(1)=\infty$; therefore, $\lim _{o \rightarrow 0} Q_{p}{ }^{*}=\infty$. Proof is complete.

Corollary 6 demonstrates that in case of non-payment of reservation fee (i.e., $o=0$ ) as well as being the possibility of exercising part of the option amount from the collector, the option amount specified by the re-manufacturer can practically be exaggerated. In the next section, the collector's decisions are surveyed.

\subsection{Collector's decisions}

Now we examine the collector's decisions. The collector, as the Stackelberg game leader, determines contract terms, i.e., option and exercise prices. By applying such a contract, the collector's profit function is no longer independent of the remanufacturing capacity outcome; therefore, the collector's profit function can be formulated as:

$$
\Pi_{C}(o, e)= \begin{cases}Q_{p} a\left(o-C_{a}-\frac{C_{e}}{a}-C_{h}\right)+\left(e-C_{t}\right) c+v\left(Q_{p} a-c\right) & Q_{p} a>c \\ Q_{p} a\left(o+e-C_{a}-\frac{C_{e}}{a}-C_{t}-C_{h}\right) & Q_{p} a \leq c\end{cases}
$$

When $Q_{p} a>c$, the re-manufacturer can exercise part of the reserved options as much as the remanufacturing capacity to make up the shortage. Thus, the collector sends $c$ items and will sell the remnant as scrap. While $Q_{p} a \leq c$ shows that notwithstanding exercising the whole options, the re-manufacturer still has usable capacity; hence, the collector will not deal with excess items. The collector maximizes its expected profit by solving $\max _{o, e} E\left[\Pi_{C}(o, e)\right]$, where

$$
\begin{aligned}
E\left(\Pi_{C}(o, e)\right)= & Q_{p} a\left(o-C_{a}-\frac{C_{e}}{a}-C_{h}\right)+v\left(\int_{0}^{Q_{p} a}\left(Q_{p} a-c\right) f(c) d c\right) \\
& +\left(e-C_{t}\right)\left(\int_{0}^{Q_{p} a} c f(c) d c+\int_{Q_{p} a}^{\infty} Q_{p} a f(c) d c\right)
\end{aligned}
$$


Theorem 4 The collector's optimal option and exercise prices can be calculated by solving:

$$
\begin{gathered}
\frac{\partial E\left(\Pi_{C}\right)}{\partial o}=Q_{p} a-\frac{o-C_{a}-\frac{C_{e}}{a}-C_{h}}{f\left(Q_{p} a\right)\left(p-C_{r e}-e-C_{i}\right)}+v a\left(\int_{0}^{Q_{p} a} f(c) d c\right)+\left(e-C_{t}\right) a\left(\int_{Q_{p} a}^{\infty} f(c) d c\right)=0 \\
\frac{\partial E\left(\Pi_{C}\right)}{\partial e}=-\frac{o\left(o-C_{a}-\frac{C_{e}}{a}-C_{h}\right)}{f\left(Q_{p} a\right)\left(p-C_{r e}-e-C_{i}\right)^{2}}+v a\left(\int_{0}^{Q_{p} a} f(c) d c\right) \\
+\left(e-C_{t}\right) a\left(\int_{Q_{p} a}^{\infty} f(c) d c\right)+\int_{0}^{Q_{p} a} c f(c) d c+\int_{Q_{p} a}^{\infty} Q_{p} a f(c) d c=0
\end{gathered}
$$

Proof By calculating Hessian matrix $H=\left[\begin{array}{cc}\frac{\partial^{2} E\left[\Pi_{C}(o)\right]}{\partial o^{2}} & \frac{\partial^{2} E\left[\Pi_{C}(o, e)\right]}{\partial o \partial e} \\ \frac{\partial^{2} E\left[\Pi_{C}(e, o)\right]}{\partial e \partial o} & \frac{\partial^{2} E\left[\Pi_{C}(e)\right]}{\partial e^{2}}\end{array}\right]$, we have:

$$
\begin{aligned}
\left|H_{1}\right| & =\frac{\partial^{2} E\left[\Pi_{C}(o)\right]}{\partial o^{2}} \\
= & -\left[\frac{2 f^{2}\left(Q_{p} a\right)\left(p-C_{r e}-e-C_{i}\right)^{2}+f^{\prime}\left(Q_{p} a\right)\left(o-C_{a}-\frac{C_{e}}{a}-C_{h}\right)}{f^{3}\left(Q_{p} a\right)\left(p-C_{r e}-e-C_{i}\right)^{3}}\right]+\frac{\left(e-C_{t}-v\right) a}{p-C_{r e}-e-C_{i}}
\end{aligned}
$$

and,

$$
\begin{aligned}
\left|H_{2}\right|= & \left(-\frac{2 f^{2}\left(Q_{p} a\right)\left(p-C_{r e}-e-C_{i}\right)^{2}+f^{\prime}\left(Q_{p} a\right)\left(o-C_{a}-\frac{C_{e}}{a}-C_{h}\right)}{f^{3}\left(Q_{p} a\right)\left(p-C_{r e}-e-C_{i}\right)^{3}}+\frac{\left(e-C_{t}-v\right) a}{p-C_{r e}-e-C_{i}}\right) \\
& \left(\frac{\left(2 f^{2}\left(Q_{p} a\right)\left(p-C_{r e}-e-C_{i}\right)+o f^{\prime}\left(Q_{p} a\right)\right)\left(o-C_{a}-\frac{C_{e}}{a}-C_{h}\right) o}{f^{3}\left(Q_{p} a\right)\left(p-C_{r e}-e-C_{i}\right)^{4}}\right. \\
& \left.+\frac{\left(e-C_{t}-v\right) a o}{\left(p-C_{r e}-e-C_{i}\right)^{2}}+a\left(1-F\left(Q_{p} a\right)\right)-\frac{o\left(1-F\left(Q_{p} a\right)\right)}{f\left(Q_{p} a\right)\left(p-C_{r e}-e-C_{i}\right)^{2}}\right) \\
& -\left(-\frac{\left(e-C_{t}-v\right) a o}{f\left(Q_{p} a\right)\left(p-C_{r e}-e-C_{i}\right)^{2}}+\frac{\left(p-C_{r e}-e-C_{i}\right)^{2}}{\left(-a\left(1-F\left(Q_{p} a\right)\right)\right.}\right. \\
& \left.-\frac{\left(2 f^{2}\left(Q_{p} a\right)\left(p-C_{r e}-e-C_{i}\right)+o f^{\prime}\left(Q_{p} a\right)\right)\left(o-C_{a}-\frac{C_{e}}{a}-C_{h}\right) o}{f^{3}\left(Q_{p} a\right)\left(p-C_{r e}-e-C_{i}\right)^{2}}\right)^{2}
\end{aligned}
$$


Table 2 Parameters related to considered examples

\begin{tabular}{lll}
\hline Parameters & First example & Second example \\
\hline$C_{r}$ & 40 & 70 \\
$C_{e}$ & 7 & 15 \\
$a$ & 0.85 & 0.9 \\
$C_{h}$ & 3 & 5 \\
$C_{r e}$ & 10 & 15 \\
$C_{i}$ & 4 & 6 \\
$C_{t}$ & 2 & 5 \\
$C_{a}$ & 15 & 25 \\
$p$ & 70 & 100 \\
$v$ & 5 & 7 \\
$c$ & $\sim N(\mu=125, \sigma=30)$ & $\sim U[150,350]$ \\
\hline
\end{tabular}

Table 3 Optimal order quantity, contract terms, and profit functions

\begin{tabular}{lcccccc}
\hline & $\Pi_{C}$ & $\Pi_{M}$ & $\Pi_{S C}$ & $Q^{*}$ & $o^{*}$ & $e^{*}$ \\
\hline First example & & & & & & \\
Centralized & 2207.221 & 1207.221 & 3414.442 & 152.15 & - & - \\
Decentralized & 1659.625 & 1339.645 & 2999.27 & 127.23 & - & - \\
Put option & 1872.748 & 1472.723 & 3345.471 & 140.21 & 16.78 & 25.34 \\
Changes (\%) & 12.84 & 9.93 & 11.54 & 10.20 & - & - \\
Second example & & & & & & \\
Centralized & 4469.156 & 1527.723 & 5996.879 & 332.48 & - & - \\
Decentralized & 3364.462 & 1745.528 & 5109.99 & 257.23 & - & - \\
Put option & 3725.482 & 1906.145 & 5631.627 & 300.24 & 27.12 & 45.89 \\
Changes (\%) & 10.73 & 9.20 & 10.21 & 16.72 & - & - \\
\hline
\end{tabular}

To show concavity of the collector's expected profit function, it is necessary to show that the Hessian matrix is negative definite. We numerically analyzed the first principal minor $\left|H_{1}\right|$ as well as the second principal minor $\left|H_{2}\right|$ and verified that $\left|H_{1}\right|<0$ and $\left|H_{2}\right|>0$ for a wide range of parameter values including our investigated test problems. Therefore, it is observed that the Hessian matrix is negative definite and according to our observations, $E\left(\Pi_{C}(o, e)\right)$ is strictly a concave function in both $o$ and $e$. By solving Eqs. (13) and (14), the optimal option and exercise prices will be obtained. Proof is complete.

\section{Insights and observations: numerical analysis}

To illustrate whether the put option contract can coordinate the RSC, we survey two numerical examples and compare each party's profit with/without the put option contract. The parameters for numerical examples and type of probability density functions for 
remanufacturing capacity are indicated in Table 2. Datasets used in the examples satisfy all the considered assumptions and models' requirements. The used data are consistent with datasets applied in the previous studies, which are mainly developed based on real cases, e.g., Govindan and Popiuc (2014). In addition, the selected values are rather general to be applied for a variety of products in the remanufacturing and refurbishing industry, albeit by scaling and some modifications. Meanwhile, equations acquired for the optimal order values are all closed-form relations that there is no need for particular software to solve. However, regardless of any system configuration, in order to solve Eqs. (13) and (14) of the developed put option contract (i.e., obtaining optimal option contract terms), any mathematics software can be used. Table 3 demonstrates optimal order quantity, contract terms, and the expected profit related to the whole system and each party under decentralized, centralized, and coordinated decision-making.

In the first example, when all parties are managed through an integrated system, i.e., centralized channel, in fact, the maximum potential of the channel is achieved. However, in reality, each party aims to pursue its interests in a decentralized manner; therefore, given Table 3, the put option contract authorizes all RSC parties to almost work integrated. Such an incentive approach has led to an increase in the amount of order $\left(Q_{p}^{*}>Q_{d}^{*}\right)$ and created much more versatility compared to the decentralized channel. This is due to the fact that the put option contract acts as a risk-sharing approach, namely, the risk of remanufacturing capacity uncertainty is divided between the re-manufacturer and collector. By a reserving strategy, the re-manufacturer can order obsolete products from the collector at a lower cost $o^{*}$, which in turn results in a boost in its order amount and a reduction in the probability of facing idle capacity. Results demonstrate that both collector and re-manufacturer will benefit almost equally if they accept the contract. However, our observations show that this amount is a little bit higher for the collector due to having a superior position in negotiation

Table 4 The influence of mean and standard deviation fluctuations on decision variables and profit functions

\begin{tabular}{lccccccc}
\hline$N(\mu, \sigma)$ & & $N(125,30)$ & $N(125,20)$ & $N(125,10)$ & $N(200,50)$ & $N(200,30)$ & $N(200,10)$ \\
\hline Centralized & $\Pi_{C}$ & 2207.221 & 2164.482 & 2121.127 & 3403.923 & 3347.522 & 3291.485 \\
Decentralized & $\Pi_{C}$ & 1659.625 & 1619.321 & 1579.372 & 2749.356 & 2697.529 & 2645.175 \\
Put option & $\Pi_{C}$ & 1872.748 & 1816.382 & 1760.241 & 2980.153 & 2913.423 & 2846.472 \\
Profit changes (\%) & $\Pi_{C}$ & 12.84 & 12.17 & 11.45 & 8.39 & 8.00 & 7.61 \\
Centralized & $\Pi_{M}$ & 1207.221 & 1326.731 & 1445.283 & 1705.374 & 1820.127 & 1935.358 \\
Decentralized & $\Pi_{M}$ & 1339.645 & 1422.757 & 1505.569 & 1812.625 & 1904.275 & 1996.275 \\
Put option & $\Pi_{M}$ & 1472.723 & 1554.133 & 1636.462 & 1958.198 & 2056.348 & 2154.925 \\
Profit changes (\%) & $\Pi_{M}$ & 9.93 & 9.23 & 8.69 & 8.03 & 7.99 & 7.95 \\
Centralized & $\Pi_{S C}$ & 3414.442 & 3491.213 & 3566.41 & 5109.297 & 5167.649 & 5226.843 \\
Decentralized & $\Pi_{S C}$ & 2999.27 & 3042.078 & 3084.941 & 4561.981 & 4601.804 & 4641.45 \\
Putoption & $\Pi_{S C}$ & 3345.471 & 3370.515 & 3396.703 & 4938.351 & 4969.771 & 5001.397 \\
Profit changes $(\%)$ & $\Pi_{S C}$ & 11.54 & 10.80 & 10.11 & 8.25 & 8.00 & 7.76 \\
Centralized & $Q_{c}{ }^{*}$ & 152.15 & 140.15 & 132.15 & 239.26 & 224.26 & 208.26 \\
Decentralized & $Q_{d}{ }^{*}$ & 127.23 & 126.23 & 125.23 & 207.43 & 204.43 & 201.43 \\
Put option & $Q_{p}{ }^{*}$ & 140.21 & 135.21 & 130.21 & 222.49 & 213.49 & 205.49 \\
Put option & $o^{*}$ & 16.78 & 16.44 & 16.1 & 17.33 & 16.81 & 16.29 \\
& $e^{*}$ & 25.34 & 24.92 & 24.5 & 26.05 & 25.45 & 24.66 \\
\hline
\end{tabular}


about put option contract terms. In contrast, without the put option contract, the re-manufacturer incurs more cost $C_{r}$ because, in case of over-stocking, it only can sell redundant products as scrap at a negligible price.

Observation 1 In a decentralized system, a put option contract better off for both parties, i.e., a win-win profit-sharing situation.

Note that the collector's optimal approach is to posit option price as low as possible, i.e., close to the refund cost paid to consumers due to returning obsolete products $\left(o^{*} \downarrow \approx C_{a}\right)$, but elicit its margin through the exercise price $\left(e^{*} \uparrow\right)$. Specifically, this demonstrates that the put option contract is able to moderate the influence of the double marginalization problem, that is, with the proximity of option price to marginal refund cost, the re-manufacturer can achieve cheap options to reserve. Thus, we have:

Observation 2 In the put option contract, the collector sets the option price as nearly low as the refund cost; in return, extracts its margin through exercise price to encourage the re-manufacturer to accept coordinated decisions.

\subsection{Sensitivity analyses}

For sensitivity analyses, first, we analyze the influence of the mean and standard deviation on order quantities, put option contract terms, and profit functions in the first example.

Table 5 The influence of acceptance rate variations on decision variables and profit functions

\begin{tabular}{|c|c|c|c|c|c|c|}
\hline \multirow[t]{2}{*}{$N(\mu, \sigma)$} & & \multicolumn{5}{|l|}{$a$} \\
\hline & & 0.75 & 0.8 & 0.85 & 0.9 & 0.95 \\
\hline Centralized & $\Pi_{C}$ & 2257.524 & 2232.356 & 2207.221 & 2182.347 & 2157.185 \\
\hline Decentralized & $\Pi_{C}$ & 1689.925 & 1674.256 & 1659.625 & 1644.158 & 1629.452 \\
\hline Put option & $\Pi_{C}$ & 1952.257 & 1912.472 & 1872.748 & 1832.621 & 1792.475 \\
\hline Profit changes(\%) & $\Pi_{C}$ & 15.52 & 14.23 & 12.84 & 11.46 & 10.00 \\
\hline Centralized & $\Pi_{M}$ & 1243.825 & 1225.345 & 1207.221 & 1189.827 & 1171.263 \\
\hline Decentralized & $\Pi_{M}$ & 1371.362 & 1355.421 & 1339.645 & 1323.412 & 1307.295 \\
\hline Put option & $\Pi_{M}$ & 1534.624 & 1503.625 & 1472.723 & 1441.284 & 1410.196 \\
\hline Profit changes(\%) & $\Pi_{M}$ & 11.91 & 10.93 & 9.93 & 8.91 & 7.87 \\
\hline Centralized & $\Pi_{S C}$ & 3501.349 & 3457.701 & 3414.442 & 3372.174 & 3328.448 \\
\hline Decentralized & $\Pi_{S C}$ & 3061.287 & 3029.677 & 2999.27 & 2967.57 & 2936.747 \\
\hline Put option & $\Pi_{S C}$ & 3486.881 & 3416.097 & 3345.471 & 3273.905 & 3202.671 \\
\hline Profit changes(\%) & $\Pi_{S C}$ & 13.90 & 12.75 & 11.54 & 10.32 & 9.06 \\
\hline Centralized & $Q_{c}{ }^{*}$ & 154.09 & 153.12 & 152.15 & 151.19 & 150.23 \\
\hline Decentralized & $Q_{d}{ }^{*}$ & 129.23 & 128.23 & 127.23 & 126.23 & 125.23 \\
\hline Put option & $Q_{p}{ }^{*}$ & 146.21 & 143.21 & 140.21 & 137.21 & 134.21 \\
\hline \multirow[t]{2}{*}{ Put option } & $o^{*}$ & 17.82 & 17.3 & 16.78 & 16.26 & 15.74 \\
\hline & $e^{*}$ & 24.48 & 24.91 & 25.34 & 25.77 & 26.2 \\
\hline
\end{tabular}


Behaviors of profit functions and decision variables by changing the mean and standard deviation of the remanufacturing capacity are indicated in Table 4.

According to Table 4, one can probe the influence of uncertainty in the remanufacturing capacity on the value of put option contract. When standard deviation decreases, this is more profitable for the re-manufacturer so that its order quantity decreases near to the mean $\left(Q_{p} \downarrow \approx \mu\right)$. Furthermore, the RSC surplus increases as well $\Pi_{S C} \uparrow$. This is related to the collector's bargaining power because the collector decides to reduce both option and exercise prices $\left(o^{*}\right.$ and $\left.e^{*} \downarrow\right)$, allowing the re-manufacturer to reserve options with less cost. As a result, in high remanufacturing capacity fluctuations, and even in a case where almost everything is considered to be certain, i.e., low capacity fluctuations (i.e., $\sigma=10$ in our examples in Table 4), participating in the put option contract results in increasing not only the parties' profit but also it boosts the RSC's profit. Therefore, we have:

Observation 3 If the standard deviation of remanufacturing capacity decreases, (i) the re-manufacturer will lessen the order quantity, and (ii) the RSC surplus will be increased.

Besides, as Table 4 demonstrates, increasing in the mean of remanufacturing capacity $(\mu \uparrow)$ leads to an increase in order quantity $Q_{p} \uparrow$, and consequently, the collector, in the equivalent case (i.e., similar standard deviation), increases both option contract terms given its bargaining power in determining option and exercise prices $\left(o^{*}\right.$ and $\left.e^{*} \uparrow\right)$. Such an increase in order quantity and option contract terms brings about more profit for both parties $\left(\Pi_{C}\right.$ and $\left.\Pi_{M} \uparrow\right)$. However, in general, the percentage increase in profit for the collector is slightly higher than the re-manufacturer due to its bargaining power. At

Table 6 The influence of remanufacturing cost variations on decision variables and profit functions

\begin{tabular}{lccccc}
\hline$N(\mu, \sigma)$ & & \multicolumn{3}{l}{$C_{r e}$} \\
\cline { 2 - 6 } & & 6 & & & \\
& & & & 10 \\
Centralized & $\Pi_{C}$ & 2321.635 & 2264.317 & 2207.221 & 2150.284 \\
Decentralized & $\Pi_{C}$ & 1715.246 & 1687.596 & 1659.625 & 1631.375 \\
Put option & $\Pi_{C}$ & 1978.614 & 1925.735 & 1872.748 & 1819.268 \\
Profit changes $(\%)$ & $\Pi_{C}$ & 15.35 & 14.11 & 12.84 & 11.52 \\
Centralized & $\Pi_{M}$ & 1339.164 & 1273.842 & 1207.221 & 1141.345 \\
Decentralized & $\Pi_{M}$ & 1423.845 & 1381.615 & 1339.645 & 1297.285 \\
Put option & $\Pi_{M}$ & 1560.861 & 1516.914 & 1472.723 & 1428.617 \\
Profit changes $(\%)$ & $\Pi_{M}$ & 9.62 & 9.79 & 9.93 & 10.12 \\
Centralized & $\Pi_{S C}$ & 3660.799 & 3538.159 & 3414.442 & 3291.629 \\
Decentralized & $\Pi_{S C}$ & 3139.091 & 3069.211 & 2999.27 & 2928.66 \\
Put option & $\Pi_{S C}$ & 3539.475 & 3442.649 & 3345.471 & 3247.885 \\
Profit changes $(\%)$ & $\Pi_{S C}$ & 12.75 & 12.17 & 11.54 & 10.90 \\
Centralized & $Q_{c}{ }^{*}$ & 158.15 & 155.15 & 152.15 & 149.15 \\
Decentralized & $Q_{d}{ }^{*}$ & 131.23 & 129.23 & 127.23 & 125.23 \\
Put option & $Q_{p}{ }^{*}$ & 148.21 & 144.21 & 140.21 & 136.21 \\
Put option & $o^{*}$ & 17.26 & 17.02 & 16.78 & 16.54 \\
& $e^{*}$ & 25.72 & 25.53 & 25.34 & 25.15 \\
\hline
\end{tabular}


the same time, it is interesting to know that the RSC surplus will be increased as well $\Pi_{S C} \uparrow$. Hence, we have:

Observation 4 Once the mean of remanufacturing capacity increases, (i) the re-manufacturer increases the order quantity, and (ii) the RSC surplus increases.

Acceptance rate is among one of the main parameters of the investigated model. Therefore, we survey the influence of changes in acceptance rate on order quantities, option contract terms, and profit functions. Table 5 shows the impact of acceptance rate fluctuations on the models' performance.

Observation 5 When acceptance rate increases, (i) the re-manufacturer decreases the order quantity, (ii) the RSC surplus decreases, and (iii) the collector decreases the option price but increases the exercise price.

As can be seen in Table 5, the higher acceptance rate causes the lower order quantity. This means that when the proportion of accepted products increases, the re-manufacturer's order quantity is reduced $Q_{p} \downarrow$. Conversely, reducing the acceptance rate by strict inspection raises the order quantity. In such a case, the collector increases the option price $o^{*} \uparrow$, but decreases the exercise price $e^{*} \downarrow$, given the examination cost and bargaining power. However, if acceptance rate increases, since the order quantity decreases, the option price will be more reduced $o^{*} \downarrow$ by the collector to persuade the re-manufacturer to use the option contract; in return, the exercise price will be increased $e^{*} \uparrow$ to compensate for the potential loss in the collector's profit.

In what follows, by changing the remanufacturing cost, we analyze the variation of decision variables and profit functions. These changes are illustrated in Table 6. Given Table 6, the more remanufacturing cost, the less tendency to order due to a decrease in marginal profit $\Pi_{M} \downarrow$. This was indicated in Corollary 2 and 3 concerned with the centralized and decentralized scenarios, which is now authentic for the ordering policy in the coordinated decision as well $Q_{p} \downarrow$. Note that reducing the order size results in negative consequences on the expected profit of each party and RSC. Increasing $C_{r e}$ reduces both contract terms

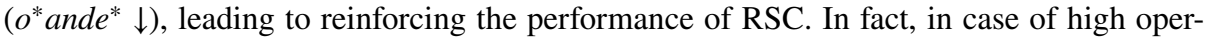
ational costs and remanufacturing capacity uncertainty, the proposed contract prevents a severe decline in the profit of each party compared to the decentralized decision. Hence, we have:

Observation 6 Once operational costs increase, e.g., remanufacturing cost, (i) the remanufacturer reduces the order quantity, and (ii) the collector lessens both option and exercise prices.

\subsection{Managerial insights}

Re-manufacturers usually face the challenge of remanufacturing capacity uncertainty due to various reasons; one of them is the recent pandemic, i.e., COVID-19. Note that ignoring such uncertainty might bewilder the RSC managers from making realistic decisions; therefore, using proper optimization approaches can help RSC managers to cope with the remanufacturing capacity uncertainties. The major purpose of this paper is to develop RSC managers' knowledge about practical approaches against remanufacturing 
capacity uncertainty. Contracting with a collector who has the ability to persuade consumers to return their end-of-life products and also has appropriate examination criteria for returned obsolete products can be a decent strategy to strengthen the resiliency of RSCs. This paper provides substantial insights toward contracting among managers of RSC parties.

Regardless of the severity of remanufacturing capacity volatility, signing a put option contract can be lucrative for both the re-manufacturer and collector compared to the decentralized decision. In this case, if fluctuation is nearly low, downstream managers are recommended to reduce both option and exercise prices (i.e., diminishing option price as approximately as the refund cost paid to consumers for bringing back their obsolete products) to let the re-manufacturer reserve options. This helps the RSC not be incurred a great detriment. Meanwhile, when collectors have no strict criteria in accepting returned end-of-life products, namely, the acceptance rate of returned products is high, we advise downstream managers to keep decreasing the option price; in return, they can increase the exercise price. This tuning of option and exercise prices results in the strong motivation for upstream to enter the contract. Besides, it should be kept in mind that if upstream party, i.e., the re-manufacturer, faces high operational costs for remanufacturing in addition to the capacity uncertainty, the attitude to remanufacture obsolete products will be decreased because of declining in profit margins. In this case, downstream managers are advised to reduce both option contract terms. This is beneficial not only for each party but also for the whole system.

\section{Conclusion}

RSC management is one of the overriding issues that can be implemented to ameliorate a set of fundamental organizational goals simultaneously (i.e., economic and environmental goals). Recently, due to the COVID-19 global pandemic, the challenges of RSC management have been exacerbated due to the increase in uncertainties and attracted the attention of many researchers. Hence, we consider a two-echelon RSC, including a re-manufacturer who, notwithstanding facing the remanufacturing capacity uncertainty, remanufactures eligible obsolete products and a collector who gathers eligible obsolete products from consumers. Different from previous papers, which have investigated the influence of option contracts and optimal contract terms (i.e., option and exercise prices) in forward supply chains under demand volatility, this paper has studied and analyzed the value of put option contract and optimal option contract terms in the RSC which deals with remanufacturing capacity uncertainty.

We demonstrate that the customized put option contract can coordinate the RSC. This conclusion is entirely new in RSCs, where remanufacturing capacity prone to disruption. Besides, our results reveal that although in the decentralized system, the re-manufacturer's order quantity from the collector because of suffering the whole risk is lower vis-a-vis the centralized system, the put option contract is able to work as a risk-sharing mechanism thanks to the adjustment of both option and exercise prices. Therefore, by offering the put option contract and determining the option price as nearly low as the marginal refund cost, the collector can motivate the re-manufacturer to augment its order quantity close to the centralized system so that both parties achieve a win-win profit-sharing situation.

This research can be extended by considering a willingness function for consumers to bring back obsolete products based on the refund cost paid by the collector. Another extension can concentrate on environmental issues so that using game-theoretic models can 
balance economic and environmental goals. Finally, channels collecting obsolete products can be considered both offline and online so that in the online channel, contrary to the offline channel, the re-manufacturer directly receives obsolete products from consumers.

Acknowledgements The authors sincerely thank the Editors and three anonymous reviewers for their invaluable comments and recommendations that have helped us to improve the paper substantially.

\section{References}

Anderson, E., Chen, B., \& Shao, L. (2017). Supplier competition with option contracts for discrete blocks of capacity. Operations Research, 65(4), 952-967.

Arani, H. V., Rabbani, M., \& Rafiei, H. (2016). A revenue-sharing option contract toward coordination of supply chains. International Journal of Production Economics, 178, 42-56.

Biswas, I., \& Avittathur, B. (2019). Channel coordination using options contract under simultaneous price and inventory competition. Transportation Research Part E: Logistics and Transportation Review, 123, 45-60.

Chen, D., Ignatius, J., Sun, D., Zhan, S., Zhou, C., Marra, M., \& Demirbag, M. (2019). Reverse logistics pricing strategy for a green supply chain: A view of customers' environmental awareness. International Journal of Production Economics, 217, 197-210.

Chen, X., Hao, G., \& Li, L. (2014). Channel coordination with a loss-averse retailer and option contracts. International Journal of Production Economics, 150, 52-57.

Chen, X., Wan, N., \& Wang, X. (2017). Flexibility and coordination in a supply chain with bidirectional option contracts and service requirement. International Journal of Production Economics, 193, 183-192.

De Giovanni, P. (2014). Environmental collaboration in a closed-loop supply chain with a reverse revenue sharing contract. Annals of Operations Research, 220(1), 135-157.

Dev, N. K., Shankar, R., \& Qaiser, F. H. (2020). Industry 4.0 and circular economy: Operational excellence for sustainable reverse supply chain performance. Resources, Conservation and Recycling, 153, 104583.

Eriksson, K. (2019). An option mechanism to coordinate a dyadic supply chain bilaterally in a multi-period setting. Omega, 88, 196-209.

Erkoc, M., \& Wu, S. D. (2005). Managing high-tech capacity expansion via reservation contracts. Production and Operations Management, 14(2), 232-251.

Feitó-Cespón, M., Sarache, W., Piedra-Jimenez, F., \& Cespón-Castro, R. (2017). Redesign of a sustainable reverse supply chain under uncertainty: A case study. Journal of Cleaner Production, 151, 206-217.

Feng, L., Govindan, K., \& Li, C. (2017). Strategic planning: Design and coordination for dual-recycling channel reverse supply chain considering consumer behavior. European Journal of Operational Research, 260(2), 601-612.

Fu, X., Dong, M., \& Han, G. (2017). Coordinating a trust-embedded two-tier supply chain by options with multiple transaction periods. International Journal of Production Research, 55(7), 2068-2082.

Goli, A., Tirkolaee, E. B., \& Weber, G. W. (2020). A perishable product sustainable supply chain network design problem with lead time and customer satisfaction using a hybrid whale-genetic algorithm. In P. Golinska-Dawson (Ed.), Logistics operations and management for recycling and reuse. (pp. 99-124). Berlin: Springer.

Golinska-Dawson, P., \& Pawlewski, P. (2018). Simulation modelling of remanufacturing process and sustainability assessment. In P. Golinska-Dawson \& F. Kübler (Eds.), Sustainability in remanufacturing operations. (pp. 141-155). Cham: Springer.

Govindan, K., Agarwal, V., Darbari, J. D., \& Jha, P. C. (2019). An integrated decision making model for the selection of sustainable forward and reverse logistic providers. Annals of Operations Research, 273(1-2), 607-650.

Govindan, K., Azevedo, S. G., Carvalho, H., \& Cruz-Machado, V. (2014). Impact of supply chain management practices on sustainability. Journal of Cleaner production, 85, 212-225.

Govindan, K., \& Popiuc, M. N. (2014). Reverse supply chain coordination by revenue sharing contract: A case for the personal computers industry. European Journal of Operational Research, 233(2), 326-336. 
Govindan, K., Popiuc, M. N., \& Diabat, A. (2013). Overview of coordination contracts within forward and reverse supply chains. Journal of Cleaner Production, 47, 319-334.

Govindan, K., \& Soleimani, H. (2017). A review of reverse logistics and closed-loop supply chains: A Journal of Cleaner Production focus. Journal of Cleaner Production, 142, 371-384.

Guo, S., Shen, B., Choi, T. M., \& Jung, S. (2017). A review on supply chain contracts in reverse logistics: Supply chain structures and channel leaderships. Journal of Cleaner Production, 144, 387-402.

Heydari, J., \& Ghasemi, M. (2018). A revenue sharing contract for reverse supply chain coordination under stochastic quality of returned products and uncertain remanufacturing capacity. Journal of Cleaner Production, 197, 607-615.

Heydari, J., Govindan, K., \& Jafari, A. (2017). Reverse and closed loop supply chain coordination by considering government role. Transportation Research Part D: Transport and Environment, 52, 379-398.

Heydari, J., Govindan, K., \& Sadeghi, R. (2018). Reverse supply chain coordination under stochastic remanufacturing capacity. International Journal of Production Economics, 202, 1-11.

Hong, I. H., Chen, P. C., \& Yu, H. T. (2016). The effects of government subsidies on decentralised reverse supply chains. International Journal of Production Research, 54(13), 3962-3977.

Hosseini-Motlagh, S. M., Nouri-Harzvili, M., Choi, T. M., \& Ebrahimi, S. (2019). Reverse supply chain systems optimization with dual channel and demand disruptions: Sustainability, CSR investment and pricing coordination. Information Sciences, 503, 606-634.

$\mathrm{Hu}, \mathrm{B} ., \mathrm{Qu}, \mathrm{J} ., \quad \&$ Meng, C. (2018). Supply chain coordination under option contracts with joint pricing under price-dependent demand. International Journal of Production Economics, 205, 74-86.

Hu, S., Dai, Y., Ma, Z. J., \& Ye, Y. S. (2016). Designing contracts for a reverse supply chain with strategic recycling behavior of consumers. International Journal of Production Economics, 180, 16-24.

Hu, Z., Tian, J., \& Feng, G. (2019). A relief supplies purchasing model based on a put option contract. Computers \& Industrial Engineering, 127, 253-262.

Hua, M., Lai, I. K. W., \& Tang, H. (2019a). Analysis of advertising and a points-exchange incentive in a reverse supply chain for unwanted medications in households based on Game Theory. International Journal of Production Economics, 217, 259-268.

Hua, S., Liu, J., Cheng, T. C. E., \& Zhai, X. (2019b). Financing and ordering strategies for a supply chain under the option contract. International Journal of Production Economics, 208, 100-121.

Jena, S. K., Sarmah, S. P., \& Sarin, S. C. (2019). Price competition between high and low brand products considering coordination strategy. Computers \& Industrial Engineering, 130, 500-511.

John, L., Gurumurthy, A., Mateen, A., \& Narayanamurthy, G. (2020). Improving the coordination in the humanitarian supply chain: Exploring the role of options contract. Annals of Operations Research. https://doi.org/10.1007/s10479-020-03778-3.

Köle, H., \& Bakal, I. S. (2017). Value of information through options contract under disruption risk. Computers \& Industrial Engineering, 103, 85-97.

Kushwaha, S., Ghosh, A., \& Rao, A. K. (2020). Collection activity channels selection in a reverse supply chain under a carbon cap-and-trade regulation. Journal of Cleaner Production, 260, 121034.

Li, C., Feng, L., \& Luo, S. (2019). Strategic introduction of an online recycling channel in the reverse supply chain with a random demand. Journal of Cleaner Production, 236, 117683.

Li, J., Luo, X., Wang, Q., \& Zhou, W. (2020a). Supply chain coordination through capacity reservation contract and quantity flexibility contract. Omega, 99, 102195.

Li, J., Wang, Z., Jiang, B., \& Kim, T. (2017a). Coordination strategies in a three-echelon reverse supply chain for economic and social benefit. Applied Mathematical Modelling, 49, 599-611.

Li, J. C., Zhou, Y. W., \& Huang, W. (2017b). Production and procurement strategies for seasonal product supply chain under yield uncertainty with commitment-option contracts. International Journal of Production Economics, 183, 208-222.

Li, Y., Deng, Q., Zhou, C., \& Feng, L. (2020b). Environmental governance strategies in a two-echelon supply chain with tax and subsidy interactions. Annals of Operations Research, 290(1), 439-462.

Liang, L., Wang, X., \& Gao, J. (2012). An option contract pricing model of relief material supply chain. Omega, 40(5), 594-600.

Liu, Y., Foscht, T., Eisingerich, A. B., \& Tsai, H. T. (2018). Strategic management of product and brand extensions: Extending corporate brands in B2B vs. B2C markets. Industrial Marketing Management, 71, 147-159.

Luo, J., \& Chen, X. (2017). Risk hedging via option contracts in a random yield supply chain. Annals of Operations Research, 257(1-2), 697-719.

Mafakheri, F., \& Nasiri, F. (2013). Revenue sharing coordination in reverse logistics. Journal of Cleaner Production, 59, 185-196. 
Mardani, A., Kannan, D., Hooker, R. E., Ozkul, S., Alrasheedi, M., \& Tirkolaee, E. B. (2020). Evaluation of green and sustainable supply chain management using structural equation modelling: A systematic review of the state of the art literature and recommendations for future research. Journal of Cleaner Production, 249, 119383.

Mishra, S., \& Singh, S. P. (2020). A stochastic disaster-resilient and sustainable reverse logistics model in big data environment. Annals of Operations Research. https://doi.org/10.1007/s10479-020-03573-0.

Nosoohi, I., \& Nookabadi, A. S. (2016). Outsource planning through option contracts with demand and cost uncertainty. European Journal of Operational Research, 250(1), 131-142.

Özçelik, G., Faruk Yılmaz, Ö., \& Betül Yeni, F. (2020). Robust optimisation for ripple effect on reverse supply chain: An industrial case study. International Journal of Production Research, 59, 245-264.

Özceylan, E., \& Paksoy, T. (2014). Fuzzy mathematical programming approaches for reverse supply chain optimization with disassembly line balancing problem. Journal of Intelligent \& Fuzzy Systems, 26(4), 1969-1985.

Paksoy, T., Özceylan, E., \& Weber, G. W. (2010). A multi objective model for optimization of a green supply chain network. In AIP conference proceedings (Vol. 1239, No. 1, pp. 311-320). American Institute of Physics.

Ritchken, P. H., \& Tapiero, C. S. (1986). Contingent claims contracting for purchasing decisions in inventory management. Operations Research, 34(6), 864-870.

Sasikumar, P., \& Kannan, G. (2009). Issues in reverse supply chain, part III: Classification and simple analysis. International Journal of Sustainable Engineering, 2(1), 2-27.

Shu, T., Huang, C., Chen, S., Wang, S., \& Lai, K. K. (2018). Trade-old-for-remanufactured closed-loop supply chains with carbon tax and government subsidies. Sustainability, 10(11), 3935.

Soleimani, H., Seyyed-Esfahani, M., \& Shirazi, M. A. (2016). A new multi-criteria scenario-based solution approach for stochastic forward/reverse supply chain network design. Annals of Operations Research, 242(2), 399-421.

Sun, D. Q., Ma, X. Y., Wang, D. J., \& Li, J. J. (2019). Principal-agent problem for returns handling in a reverse supply chain with one manufacturer and two competing dealers. Applied Mathematical Modelling, 66, 118-140.

Tirkolaee, E. B., Abbasian, P., \& Weber, G. W. (2021). Sustainable fuzzy multi-trip location-routing problem for medical waste management during the COVID-19 outbreak. Science of the Total Environment, $756,143607$.

Uğurlu, K. (2018). Dynamic optimal contract under parameter uncertainty with risk-averse agent and principal. Turkish Journal of Mathematics, 42(3), 977-992.

Uğurlu, K. (2020). Robust utility maximization of terminal wealth with drift and volatility uncertainty. Optimization. https://doi.org/10.1080/02331934.2020.1774586.

Van Engeland, J., Beliën, J., De Boeck, L., \& De Jaeger, S. (2020). Literature review: Strategic network optimization models in waste reverse supply chains. Omega, 91, 102012.

Wang, C., Chen, J., \& Chen, X. (2017). Pricing and order decisions with option contracts in the presence of customer returns. International Journal of Production Economics, 193, 422-436.

Wang, C., Chen, J., \& Chen, X. (2019a). The impact of customer returns and bidirectional option contract on refund price and order decisions. European Journal of Operational Research, 274(1), 267-279.

Wang, C., Chen, J., Wang, L., \& Luo, J. (2019b). Supply chain coordination with put option contracts and customer returns. Journal of the Operational Research Society. https://doi.org/10.1080/01605682. 2019.1599703.

Wang, C., \& Chen, X. (2017). Option pricing and coordination in the fresh produce supply chain with portfolio contracts. Annals of Operations Research, 248(1-2), 471-491.

Wang, C., \& Chen, X. (2018). Joint order and pricing decisions for fresh produce with put option contracts. Journal of the Operational Research Society, 69(3), 474-484.

Wang, N., He, Q., \& Jiang, B. (2019c). Hybrid closed-loop supply chains with competition in recycling and product markets. International Journal of Production Economics, 217, 246-258.

Wang, Q., \& Tsao, D. B. (2006). Supply contract with bidirectional options: The buyer's perspective. International Journal of Production Economics, 101(1), 30-52.

Wang, Z., Huo, J., \& Duan, Y. (2019d). Impact of government subsidies on pricing strategies in reverse supply chains of waste electrical and electronic equipment. Waste Management, 95, 440-449.

Weraikat, D., Zanjani, M. K., \& Lehoux, N. (2016). Coordinating a green reverse supply chain in pharmaceutical sector by negotiation. Computers \& Industrial Engineering, 93, 67-77.

Wu, D., Chen, J., Li, P., \& Zhang, R. (2020). Contract coordination of dual channel reverse supply chain considering service level. Journal of Cleaner Production, 260, 121071. 
Xie, J., Liang, L., Liu, L., \& Ieromonachou, P. (2017). Coordination contracts of dual-channel with cooperation advertising in closed-loop supply chains. International Journal of Production Economics, 183, $528-538$.

$\mathrm{Xu}, \mathrm{H}$. (2010). Managing production and procurement through option contracts in supply chains with random yield. International Journal of Production Economics, 126(2), 306-313.

Zarbakhshnia, N., Kannan, D., Mavi, R. K., \& Soleimani, H. (2020). A novel sustainable multi-objective optimization model for forward and reverse logistics system under demand uncertainty. Annals of Operations Research, 295(2), 843-880.

Zhao, Y., Choi, T. M., Cheng, T. C. E., \& Wang, S. (2018). Supply option contracts with spot market and demand information updating. European Journal of Operational Research, 266(3), 1062-1071.

Zhao, Y., Ma, L., Xie, G., \& Cheng, T. C. E. (2013). Coordination of supply chains with bidirectional option contracts. European Journal of Operational Research, 229(2), 375-381.

Publisher's Note Springer Nature remains neutral with regard to jurisdictional claims in published maps and institutional affiliations. 